\title{
SYSTEMATIC REVIEW OPEN Physical and functional performance assessment in pediatric oncology: a systematic review
}

Regine Söntgerath ${ }^{1}$, Julia Däggelmann ${ }^{2}$, Sabine V. Kesting ${ }^{3,4}$, Corina S. Rueegg ${ }^{5}$, Torge-Christian Wittke ${ }^{6}$, Simon Reich ${ }^{7}$, Katharina G. Eckert ${ }^{8}$, Sandra Stoessel ${ }^{9}$, Carolina Chamorro-Viña ${ }^{10}$, Joachim Wiskemann ${ }^{7}$, Peter Wright ${ }^{11}$, Anna Senn-Malashonak ${ }^{12}$, Vanessa Oschwald ${ }^{2}$, Anne-Marie Till ${ }^{13}$ and Miriam Götte ${ }^{14}{ }^{14}$

BACKGROUND: Research indicates reduced physical performance from diagnosis into survivorship of pediatric cancer patients. However, there is no systematic information or guideline available on the methods to assess physical performance and function in this population. The purpose was to systematically compile and describe assessments of physical performance and function in patients and survivors of pediatric cancer, including cardiorespiratory fitness, muscle strength, speed, balance, flexibility, functional mobility, gait and motor performance test batteries.

METHODS: We searched the databases PubMed, SPORTDiscus, and Cochrane Database and performed abstract and full-text selection of 2619 articles according to the Cochrane Handbook of Systematic Reviews. Information on patients characteristics, assessments, information on validity and reliability, and relevant references was extracted.

RESULTS: In summary, 63 different assessments were found in 149 studies including 11639 participants. Most studies evaluated cardiorespiratory fitness and muscle strength with the majority conducted off treatment. Some outcomes (e.g. speed) and diagnoses (e.g. neuroblastoma) were severely underrepresented. With the exception of gait, leukemia patients represented the largest group of individuals tested.

CONCLUSIONS: Insufficient data and patient heterogeneity complicate uniform recommendations for assessments. Our results support researchers and practitioners in selecting appropriate assessment to meet their specific research questions or individual daily practice needs.

Pediatric Research (2022) 91:743-756; https://doi.org/10.1038/s41390-021-01523-5

\section{IMPACT:}

- This systematic review includes 149 studies and provides a comprehensive summary of 63 assessments to evaluate cardiorespiratory fitness, muscle strength, speed, balance, flexibility, functional mobility, gait or motor performance test batteries in patients and survivors of pediatric cancer.

- We present the most studied fields within the pediatric cancer population, which are cardiorespiratory fitness and muscle strength, off treatment phase, and leukemia patients.

- We propose research priorities by identification of subgroups in terms of cancer type, phase of treatment, and outcome of interest that are underrepresented in studies currently available.

\section{INTRODUCTION}

Age-appropriate healthy physical and functional development of infants, children, and adolescents is an important prerequisite for participation in physical activity and sports representing a major determinant of a long-term active and healthy lifestyle. ${ }^{1}$ Physical and functional performance of children and adolescents during and after cancer treatment has been the interest of a growing number of studies during past decades. Current literature presents increasing evidence that childhood cancer patients and survivors are challenged by physical performance limitations such as

\footnotetext{
${ }^{1}$ Department of Pediatric Oncology, Hematology and Hemostaseology, University Hospital Leipzig, Leipzig, Germany; ${ }^{2}$ Department of Molecular and Cellular Sports Medicine, Institute of Cardiology and Sports Medicine, German Sport University Cologne, Cologne, Germany; ${ }^{3}$ Institute of Preventive Pediatrics, Department of Sport and Health Sciences, Technical University of Munich, Munich, Germany; ${ }^{4}$ Kinderklinik München Schwabing, TUM School of Medicine, Department of Pediatrics and Children's Cancer Research Center, Technical University of Munich, Munich, Germany; ${ }^{5}$ Oslo Centre for Biostatistics and Epidemiology, Oslo University Hospital, Oslo, Norway; ${ }^{6}$ Krukenberg Cancer Center, University Medicine Halle (Saale), Halle, Germany; ${ }^{7}$ Working Group Exercise Oncology Division of Medical Oncology, University Clinic Heidelberg and National Centre for Tumor Diseases (NCT), Heidelberg, Germany; ${ }^{8}$ Department of Health Management \& Public Health, IST University of Applied Sciences Düsseldorf, Düsseldorf, Germany; ${ }^{9}$ Center for Pediatric and Adolescent Medicine, Childhood Cancer Center, University Medical Center Mainz, Mainz, Germany; ${ }^{10}$ Faculty of Kinesiology, Calgary, Alberta, Canada; ${ }^{11}$ Department of Sport, Health Sciences and Social Work, Oxford Brookes University, Oxford, UK; ${ }^{12}$ Department of Pediatric Oncology, Hematology and Hemostaseology, Goethe University Clinic

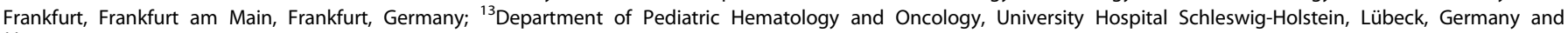
${ }^{14}$ Department of Pediatric Hematology and Oncology, University Hospital Essen, Pediatrics III, Essen, Germany

Correspondence: Miriam Götte (miriam.goette@uk-essen.de)

These authors contributed equally: Regine Söntgerath, Julia Däggelmann
}

Received: 8 January 2021 Revised: 26 February 2021 Accepted: 29 March 2021

Published online: 15 April 2021 
reduced cardiorespiratory fitness, muscle strength, balance, gait, functional mobility, and flexibility/range of motion. ${ }^{2-4}$ Influencing factors for these impairments might be the cancer itself, side effects of medical therapy, and inactivity during and after treatment. ${ }^{5}$ Study results demonstrate reduced physical performance shortly after diagnosis, ${ }^{6}$ during acute treatment, ${ }^{3}$ and persisting throughout survivorship. ${ }^{7}$ This is specifically concerning as physical performance limitations are linked to an increased incidence of unemployment and low income. ${ }^{8}$

At the same time, preliminary exercise intervention studies provide promising results in terms of efficacy to improve physical performance and fitness. ${ }^{9-11}$ However, evaluation of those positive effects found in research interventions with childhood cancer populations is difficult due to the large number of different physical and functional performance assessments that have been used in pediatric oncology research. An overview of assessments could help future researchers when planning a study on exercise and fitness in child and adolescent cancer patients and survivors. Few attempts have been done to summarize and describe tests performed and used in this population. Grimshaw et al. ${ }^{12}$ summarized subjective and objective tools to measure physical function and physical activity in the age group 0-18 years with a focus on the evaluation of measurement properties. Another group of researchers ${ }^{13}$ listed evaluation tools used in childhood cancer physical activity/exercise studies or community-based programs that assess motor performance, physical literacy, wellbeing, quality of life (QoL), and health behavior, but assessments of physical performance and fitness were excluded. However, no review has predefined the categories of physical and functional performance relevant to health and exercise science ${ }^{14}$ in order to systematically search and summarize them. Thus, the aim of the present systematic review is to summarize in detail all assessments used to measure cardiorespiratory fitness, muscle strength, speed, balance, flexibility, functional mobility, gait, and motor performance in interventional and non-interventional studies with childhood cancer patients and survivors. This summary is intended to support researchers and therapists in selecting the most appropriate assessments for their individual purposes and needs.

\section{MATERIALS AND METHODS}

This paper was written according to the Preferred Reporting Items for Systematic Reviews and Meta-Analyses (PRISMA Statement). ${ }^{15}$

Data sources and searches

We systematically searched PubMed, Cochrane Central Register of Controlled Trials and SPORTDiscus from database inception to 13 February 2020. The search strategy (see Appendix 1) included Medical Subject Headings with terms and text words to identify studies conducted with children, adolescents, or adults during or after childhood cancer treatment who underwent any assessment for either physical or functional performance. In addition, references of relevant reviews and reference lists of included studies were screened. The specific outcomes of interest were assessments for cardiorespiratory fitness, muscle strength, speed, balance, flexibility, functional mobility, gait, and motor performance assessed in test batteries. Motor performance test batteries measuring physical performance provide an important overview of performance levels and motor development and are of great importance in children and adolescents. In pediatric oncology and chronically ill children, they are usually assessing performance of general motor skills. Data on validity and reliability of the included assessments in pediatric cancer patients and survivors were extracted from the included full texts and associated references.

Study selection

After exclusion of duplicates, three teams of two researchers each independently reviewed titles and abstracts of the identified articles. Studies were excluded for the following reasons: (i) less than $75 \%$ of the population were diagnosed with cancer $<21$ years, (ii) the outcome was no measure of either physical or functional performance as defined above, (iii) any non-original articles (e.g. reviews, congress abstracts, commentaries or letters without data), (iv) duplicates that were not identified as such before, (v) studies without description of assessment used (vi) studies/assessment with less than five participants, or (vii) fulltexts that were not available in English or German. We included all types of studies and had no restriction in terms of publication date. In case of disagreement between the two reviewers, articles were discussed between these two and if no consensus could be reached, a third reviewer was consulted. After final inclusion of abstracts, the respective full texts were reviewed independently as described above.

Data extraction, synthesis, and analysis

Relevant data from the included full texts were extracted and organized into standardized data tables. During the data extraction process, the following information was extracted from all texts: study citation, characteristics of the study population (sample sizes, age ranges, diagnoses, stage of cancer treatment), assessments used and their measurement properties, and relevant references for further information. In terms of measurement properties, information regarding validity and reliability of the assessment was only extracted if those were evaluated in the childhood cancer study sample. Based on these tables, assessments were sorted into predefined health-related and skill-related categories as defined by the American College of Sports Medicine $^{14}$ (cardiorespiratory fitness, muscle strength, speed, balance, flexibility). In addition to these main motor domains, functional mobility, gait, and motor performance test batteries which have been identified to be of high relevance for the population of children with cancer ${ }^{3,16,17}$ and for coping with everyday life and participation with peers ${ }^{18}$ were included. For each single assessment (e.g. 6-minute walk test (6MWT) in the category cardiorespiratory fitness) all information about the study participants was merged from the studies using this particular assessment. Diagnoses were grouped into categories, i.e. leukemia/lymphoma (as hematological tumors), bone tumor, CNS tumors, and others. This classification was made because individuals after bone tumors or CNS tumors are known to suffer from more severe motor deficits due to the underlying disease. ${ }^{19}$ In case of insufficient information, study authors were contacted via email. If no answer was received, information was taken from the manuscript as specific as possible.

\section{RESULTS}

Literature search results

Figure 1 displays the flow of studies through the review process. After 81 duplicates were removed, 2619 records underwent abstract screening, of which 2295 were excluded and 324 articles were retained for full-text review. Additional 40 articles, identified through reference list screening of reviews and other sources, were then added to full-test screening, resulting in 364 articles. Of those, 215 articles were excluded with reasons and 149 full texts $^{3,6,10,20-165}$ (see Appendix 2 for detailed study information) were included for data extraction, representing $5.7 \%$ of screened abstracts and $40.7 \%$ of screened full text articles. Agreement between the reviewers for abstract screening ranged between 82 and $96 \%$ and for the full text screening between 84 and $93 \%$.

Study characteristics

In summary, all 149 studies, describing 63 different assessment methods, included in this systematic review were published between 1984 and 2020. Of those, $n=1$ study was published between 1984 and 1990, $n=18$ studies between 1991 and 2000, 


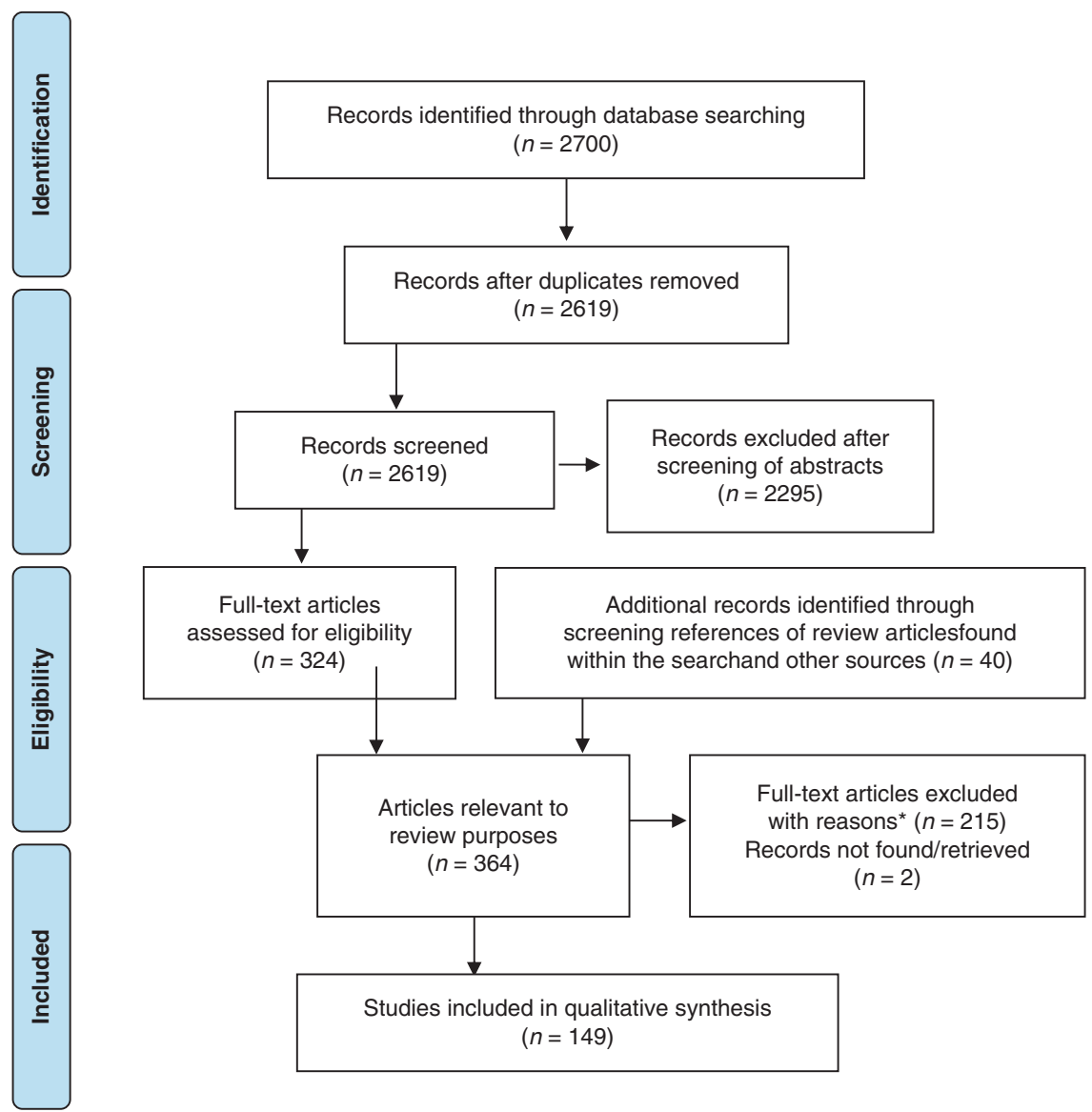

Fig. 1 PRISMA flow diagram showing the reference selection process. ${ }^{*}$ Reasons for exclusion: less than $75 \%$ of the population were diagnosed with cancer measure of either physical or functional performance $(n=55)$, any non-original articles (e.g. reviews, congress abstracts, commentaries or letters without data) $(n=31)$, duplicates that were not identified as such before $(n=10)$, (v) studies without description of assessment used ( $n=9)$, (vi) studies/assessment with less than five participants $(n=11)$, or (vii) full-texts that were not available in English or German ( $n=13)$.

$n=48$ studies between 2001 and 2010, and $n=82$ studies between 2011 and 2020. The studies included a total number of $n$ $=11,639$ participants being treated for childhood cancer and/or having received hematopoietic stem cell transplantation (HSCT). Of these, $n=6295$ (54.1\%) were diagnosed with leukemia, $n=$ $1408(12.1 \%)$ with lymphoma, $n=1271$ (10.9\%) with tumors of the central nervous system (CNS), $n=76(0.7 \%)$ with neuroblastoma, $n=12(0.1 \%)$ with retinoblastoma, $n=149(1.3 \%)$ with renal tumor, $n=3(0.03 \%)$ with hepatoblastoma, $n=692$ (5.9\%) with bone tumor, $n=68(0.6 \%)$ with soft tissue sarcoma, $n=34(0.3 \%)$ with germ cell tumor, and $n=56(0.5 \%)$ with other malignancies. In $n=1575$ cases (13.5\%) a classification was not possible due to a missing detailed description in the full texts. While 22 studies (14.8\%) took place during active cancer treatment, 9 studies (6.0\%) were conducted during maintenance therapy and 99 studies $(66.4 \%)$ after treatment. Nineteen studies (12.8\%) included participants during different phases of medical treatment. The age of participants ranged between 1.0 and 68.3 years. Most studies analyzed a parameter of cardiorespiratory fitness, followed by strength, motor performance in test batteries, flexibility, functional mobility, gait and balance. Only five studies evaluated speed (Fig. 2). Considering the incidence of childhood cancer, ${ }^{166}$ the number of individuals tested in the categories of physical performance and function deviates from the incidence of the tumor type. An overview of the distribution of diagnoses within each category and overall childhood cancer incidence rates are presented in Fig. 3. Some physical performance categories, like cardiorespiratory fitness and muscle strength, were tested in many different types of cancer. However, in all categories, with the exception of gait, individuals with leukemia were overrepresented. For gait and motor performance test batteries, the inclusion of bone tumor patients was far above the percentage incidence of bone tumors, whereas in the other six categories, bone tumors as well as other solid tumors were investigated less frequently.

Results on methods to assess physical and functional performance In total, 63 different assessments were used to evaluate at least one of the eight categories of physical performance and/or function. Between 2 and 16 different assessments were used to evaluate one of the eight categories. The largest heterogeneity in assessment type, calculated as the number of assessment types divided by the number of studies, was in gait with 8 different assessments from 19 studies (0.42), balance with 6 different assessments from 15 studies, and speed with 2 different assessments from 5 studies (0.40). To assess motor performance with test batteries, 16 different test batteries were used in 49 studies (0.33). Strength was evaluated with 16 different measures in 57 studies (0.28) and mobility with 5 assessments in 29 studies (0.17). The greatest homogeneity in measurement techniques was for cardiorespiratory fitness $(0.10)$ and flexibility (0.08) ( 7 and 3 different methods in 68 and 40 studies, respectively). The different methods are summarized in Tables 1-8 with more details in Appendices 3-10.

Cardiorespiratory fitness (also referred to as endurance, aerobic fitness, or aerobic capacity) was evaluated by a total of 68 studies 


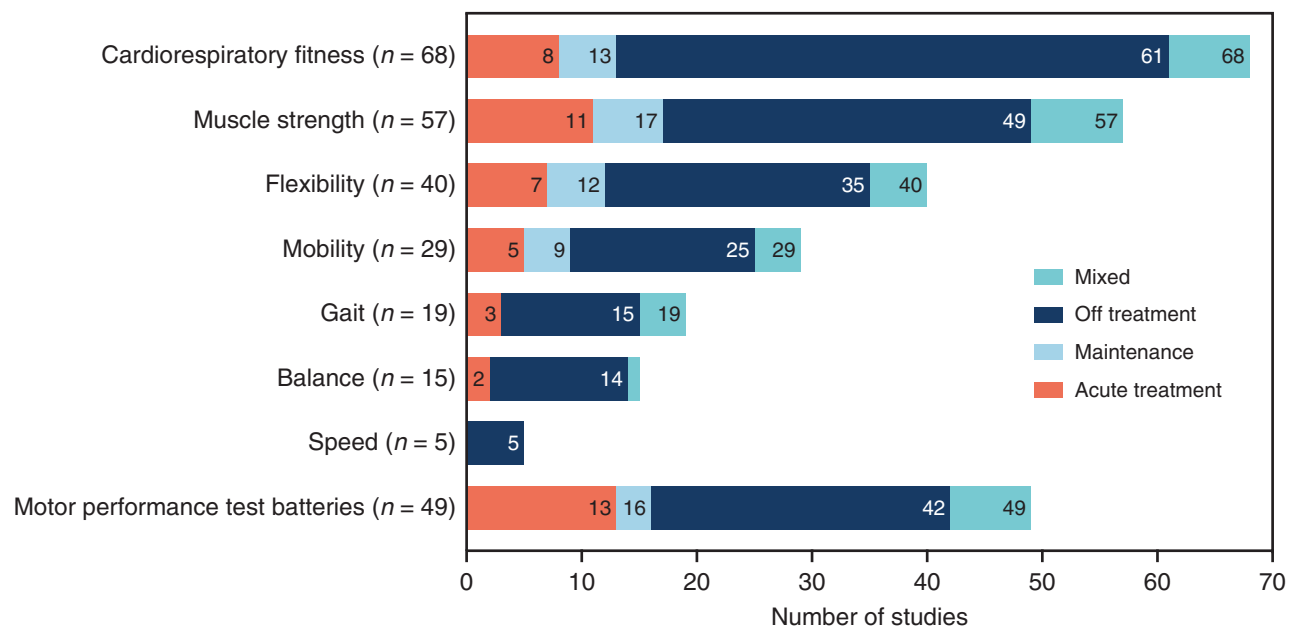

Fig. 2 Number of studies for each outcome measure, indicating the phase of therapy in which the studies were conducted. Please note: The sum of assessments in Fig. $2(n=282)$ is greater than the number of all included studies $(n=149)$, because in many studies assessments from several categories were included.

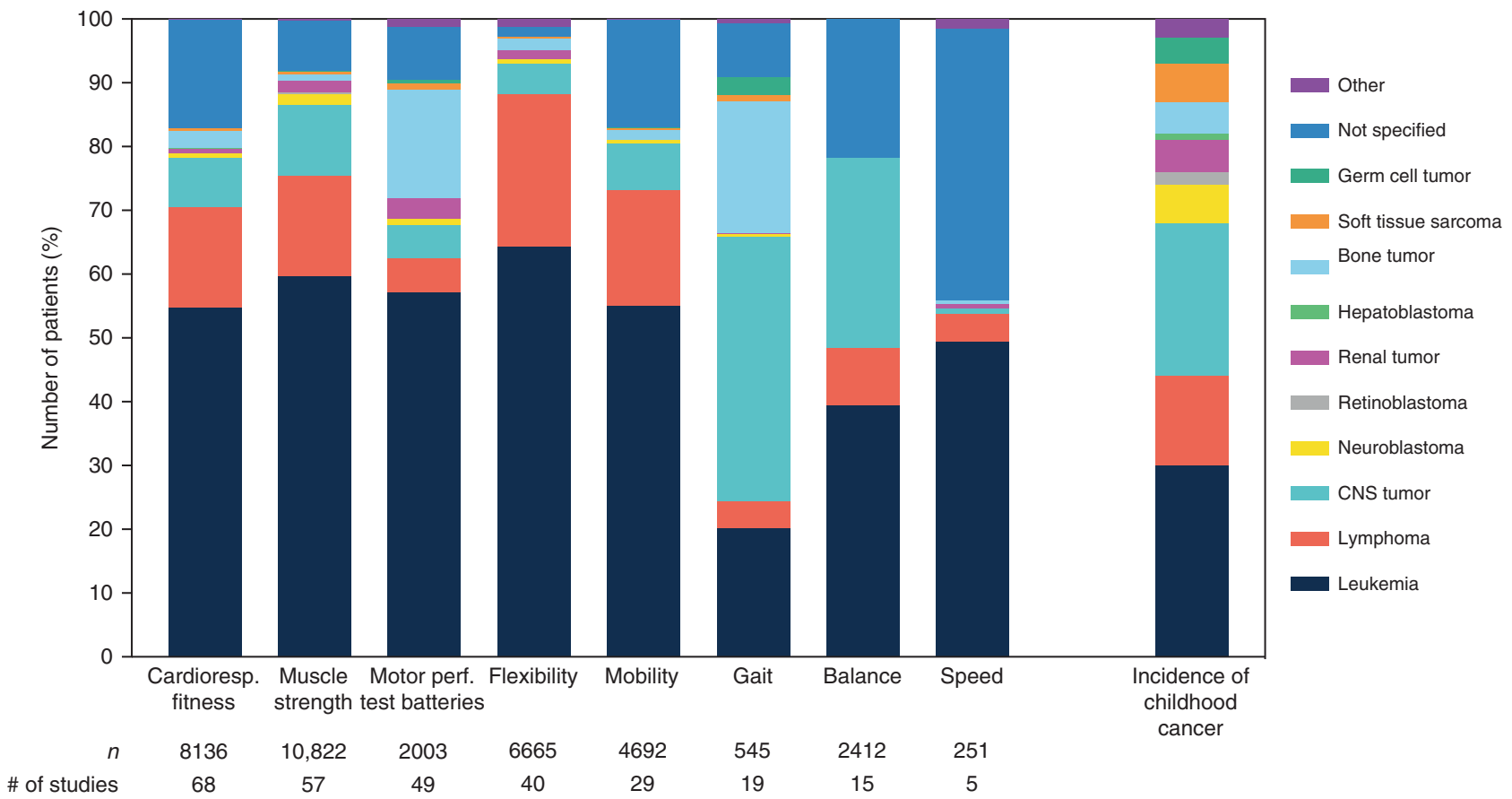

Fig. 3 Distribution of the types of cancer (\%) that were included in the assessments of the eight categories of physical performance and function. The bar on the far right shows the incidence of childhood cancer as a reference. Note: Number of persons tested specified here (e.g. $n=8136$ for cardiorespiratory fitness) differs from number of study participants ( $n=7936$, see section on cardiorespiratory fitness above), because some study participants were tested using several test methods.

including $n=7936$ patients/survivors using 7 lab- and field-based assessment methods (Table 1 and Appendix 3). While the most frequently used assessments (maximal cardiopulmonary exercise test (CPET) and 6MWT) were administered in all diagnostic subgroups during all phases of treatment and a very wide age range, no other assessment was applied during treatment. In terms of measurement properties, the 9MWT has shown to be both reliable and valid in the pediatric oncology population. ${ }^{92,94}$

Muscle strength (i.e. muscular endurance or power) was evaluated in 57 studies including $n=5679$ childhood cancer patients and survivors using 16 different laboratory and fieldbased assessment methods (Table 2 and Appendix 4). Muscle strength was assessed either by laboratory or field tests focusing on the upper and lower extremities as well as several assessments of core and back muscle strength. While leukemia and/or lymphoma patients and off treatment phase were included in all assessments, some researchers included other cancer diagnoses or phases of medical treatment. In addition, a wide range of age groups was assessed. Isokinetic dynamometry, hand-held dynamometry, and repetition maximum tests are the only assessments that have been shown to be reliable with pediatric cancer cohorts. $^{92,96}$

Speed (ability to perform a movement within a short period of time ${ }^{14}$ ) was assessed in five studies using two different assessments, which comprised a total of $n=251$ childhood cancer survivors aged between 6 and 30 years (Table 3 and Appendix 5). All testing took place after cessation of treatment. Only field tests, namely shuttle run tests, as the $10 \times 5 \mathrm{~m}$ shuttle run and the $4 \times 10$ 


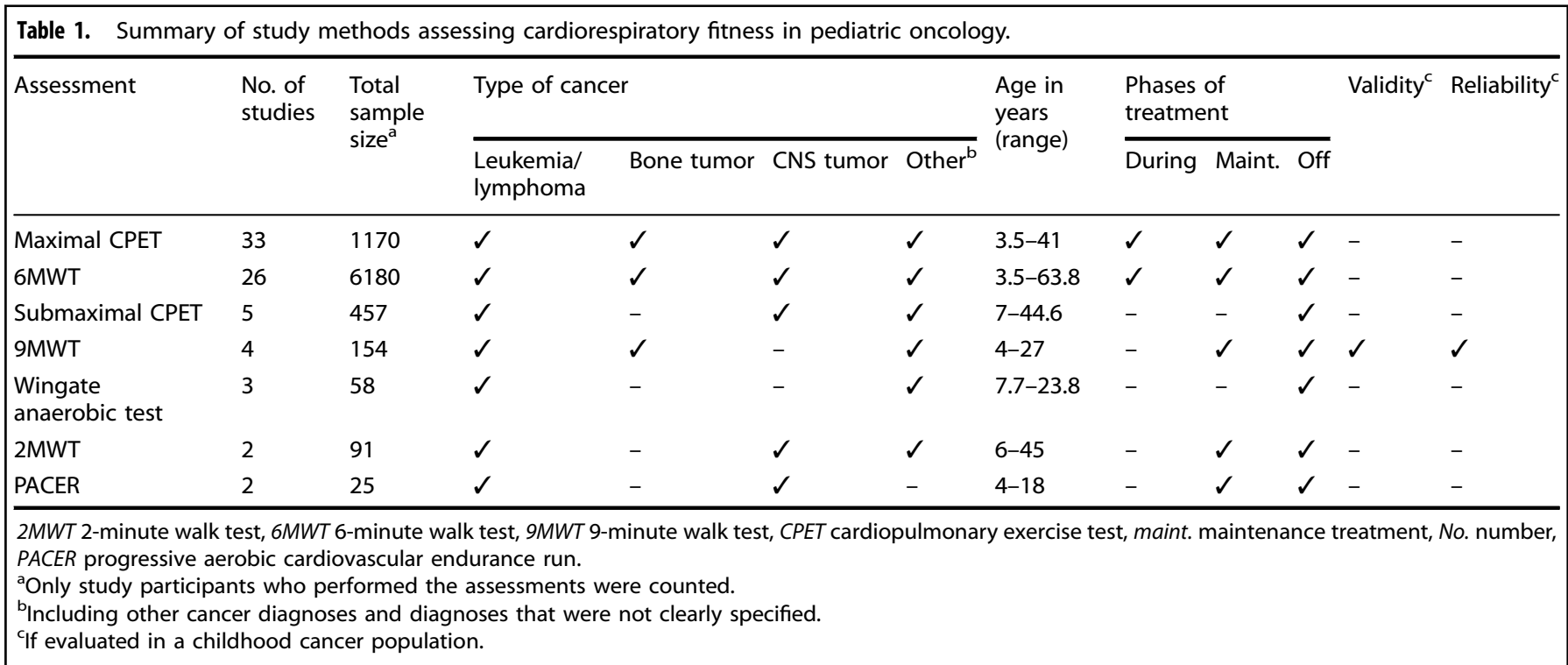

$\mathrm{m}$ shuttle run and short distance runs, namely a $60 \mathrm{~m}$ run test, were administered. Shuttle run tests were not performed with patients who either present with CNS cancer or bone tumors.

Balance was assessed in 15 studies using six different tests including a total of $n=2412$ patients/survivors (Table 4 and Appendix 6). The nature of assessments was based on posturography and non-posturography methods. While posturography was only performed after medical treatment, two studies conducted balance tests during treatment. ${ }^{114,148}$ Bone tumor patients were only included in one study, ${ }^{103}$ while CNS cancer cohorts were the population of main interest. In terms of age, a wide spectrum including very young children, as well as older adult survivors of childhood cancer (up to an age of 63 years) were analyzed. No information was available on the validity or reliability of any balance assessment in the pediatric oncology population.

Flexibility was assessed in 40 studies, applying three different test methods which included a total of $n=4309$ patients/survivors (Table 5 and Appendix 7). Goniometry, measuring ankle joint range of motion, was performed in most studies including a large number of participants of all ages, with a wide range of diagnoses during all phases of medical treatment. Reliability was analyzed in children with acute lymphoblastic leukemia (ALL) in two studies. ${ }^{92,158}$ In addition, two other flexibility tests measuring hip flexion and trunk flexibility were performed with leukemia/ lymphoma, CNS tumor, and other childhood cancer patients and survivors. However, trunk flexibility assessment was only conducted in one study including (young) adults after childhood cancer treatment ${ }^{62}$ while the sit and reach test was applied more often with all age groups during all phases of treatment. Measurement properties were not analyzed within the childhood cancer population.

Functional mobility was measured in 29 studies including a total of $n=4421$ patients using five different assessment methods (Table 6 and Appendix 8). Of these, the Timed Up and Go Test (TUG) was administered in two ways: covering either a $3 \mathrm{~m}$ or a 10 $\mathrm{m}$ distance. While the TUG $3 \mathrm{~m}$ and the Timed Up and Down Stairs Test (TUDS) were applied within several studies, including various childhood cancer diagnoses during all phases of medical treatment, the TUG $10 \mathrm{~m}$ was only used with ALL patients during maintenance and/or off treatment. ${ }^{128,130,131}$ Two additional functional tests (stand up from bed rest exam and floor to stand performance test) were both administered within one study each during treatment for childhood cancer. ${ }^{79,148}$ Only the TUG $3 \mathrm{~m}$ was performed with older (up to age 64 years) adult survivors of childhood cancer, while all other assessments were conducted with children, adolescents, and young adults. The TUG $3 \mathrm{~m}$ demonstrated high validity and reliability ${ }^{96}$ while the TUDS and TUG $10 \mathrm{~m}$ both have shown to be reliable. ${ }^{131}$

Gait analyses was carried out in 19 studies, using eight different methods including a total of $n=545$ patients/survivors (Table 7 and Appendix 9). A wide variety of systems were used to assess gait in childhood cancer populations. While few studies used video-recording, partly in combination with force platforms and sometimes electromyography (EMG) measurements, single studies used specific systems, visual observation, or a timed walking test. Except for the EMG analysis of gait and visual observation, all systems assessed gait within various groups of childhood cancer diagnoses. However, only two methods (GAITRite and visual observation) were performed during treatment. ${ }^{50,148,150}$ No information is available on validity and/or reliability of any gait analysis system in the pediatric oncology population.

Motor performance test batteries were assessed in 49 studies using 16 different motor test batteries and included a total of 1955 participants (Table 8 and Appendix 10). Most tests were applied in leukemia/lymphoma cohorts after medical treatment. Except for the Functional Mobility Assessment (FMA), which was used in survivors up to age 42 years, all motor test batteries are designed for children and adolescents. Considering all three Bruininks-Oseretsky Test (BOT) versions (BOTMP, BOT-2, BOT-2 $\mathrm{SF}$ ), the BOT and MOON-Test (Motor performance in pediatric oncology) are the only motor performance test batteries evaluated for feasibility in all diagnosis groups and during all phases of cancer treatment and with young adults. The Gross Motor Function Measure (GFMF) and GFMF-ALL Test Battery are the only assessments that have been evaluated in terms of measurement properties in pediatric oncology populations, ${ }^{160}$ while the University of Québec in Chicoutimi-University of Québec in Montréal (UQAC-UQAM) has been validated using the Jackknife method. $^{85}$

\section{DISCUSSION}

This systematic review summarizes the available studies assessing physical performance and function in pediatric cancer patients and survivors. Based on the included 149 studies with 11,639 participants and 63 different assessment tools, we found important characteristics of the distribution and characteristics of the assessments (Table 9). The majority of studies (45.6\%) 


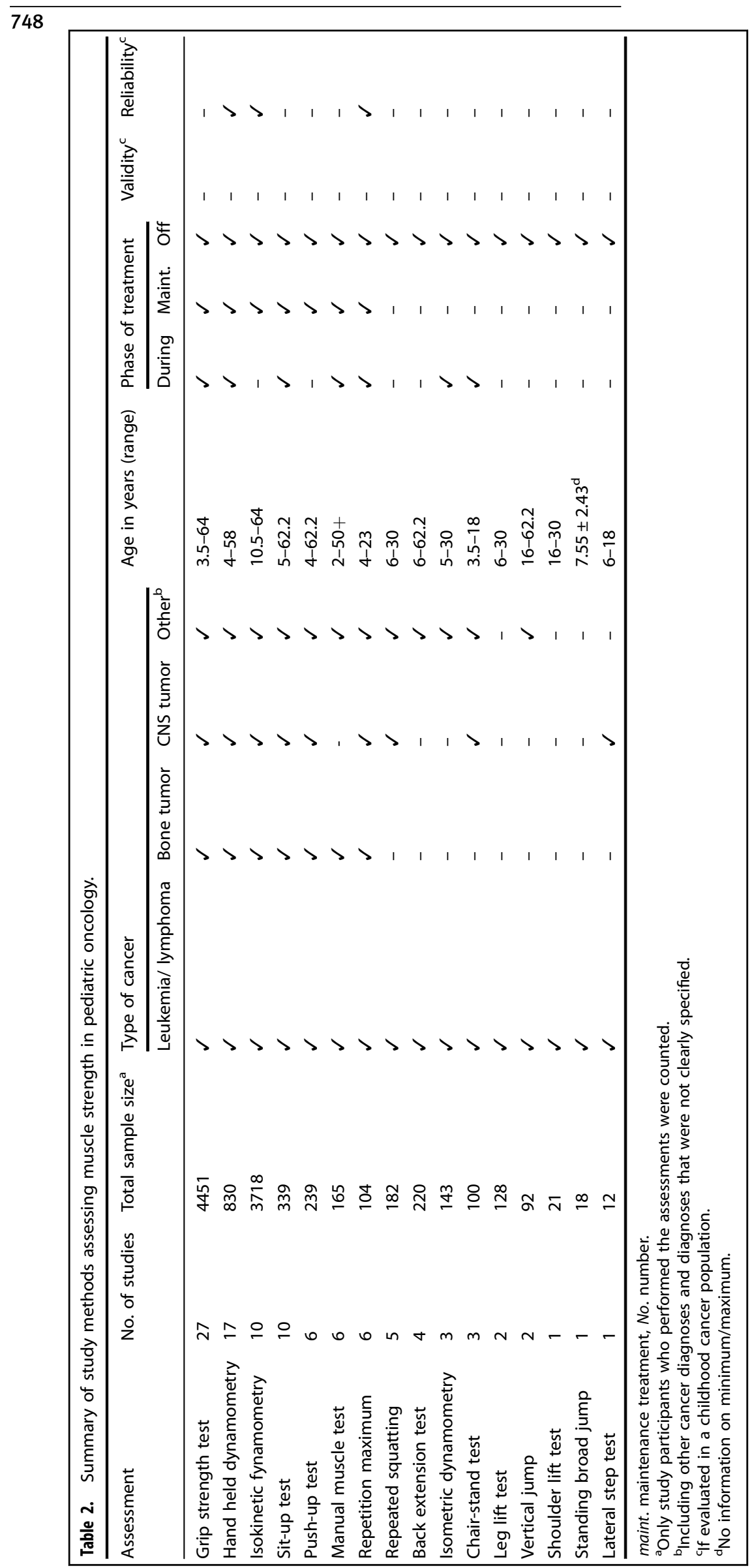



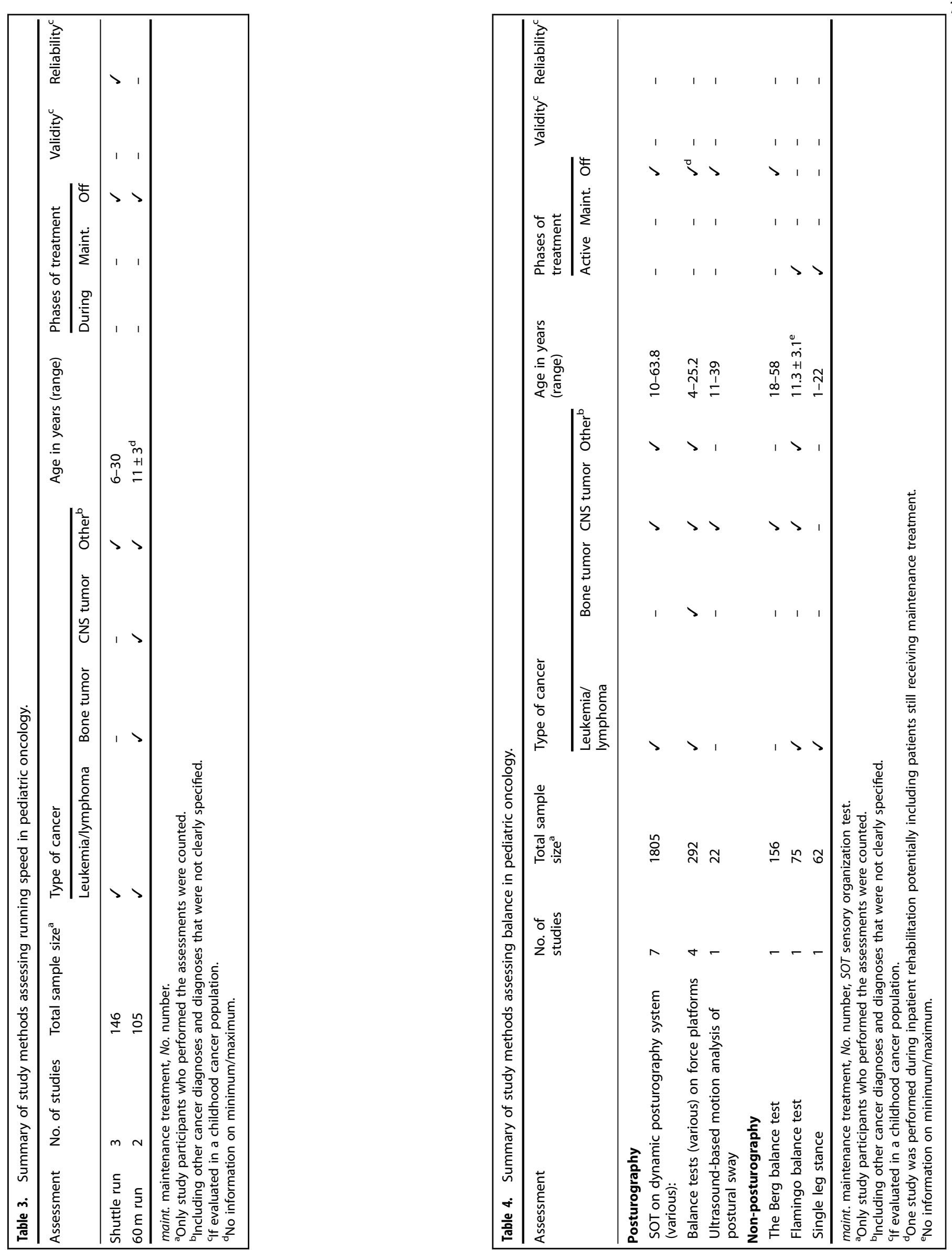
Physical and functional performance assessment in pediatric oncology: a...

R Söntgerath et al.

Table 5. Summary of study methods assessing flexibility in pediatric oncology.

\begin{tabular}{|c|c|c|c|c|c|c|c|c|c|c|c|c|}
\hline \multirow[t]{2}{*}{ Assessment } & \multirow[t]{2}{*}{$\begin{array}{l}\text { No. of } \\
\text { studies }\end{array}$} & \multirow{2}{*}{$\begin{array}{l}\text { Total } \\
\text { sample } \\
\text { size }^{a}\end{array}$} & \multicolumn{4}{|c|}{ Type of cancer } & \multirow[t]{2}{*}{$\begin{array}{l}\text { Age in years } \\
\text { (range) }\end{array}$} & \multicolumn{3}{|c|}{$\begin{array}{l}\text { Phases of } \\
\text { treatment }\end{array}$} & \multirow[t]{2}{*}{ Validity $^{c}$} & \multirow[t]{2}{*}{ Reliability' } \\
\hline & & & $\begin{array}{l}\text { Leukemia/ } \\
\text { lymphoma }\end{array}$ & Bone tumor & CNS tumor & Other $^{b}$ & & During & Maint. & $\overline{\text { Off }}$ & & \\
\hline Goniometry & 33 & 3764 & $\checkmark$ & $\checkmark$ & $\checkmark$ & $\checkmark$ & $1-64$ & $\checkmark$ & $\checkmark$ & $\checkmark$ & - & $\checkmark$ \\
\hline Sit and reach & 12 & 2830 & $\checkmark$ & $\checkmark$ & $\checkmark$ & $\checkmark$ & $4-64$ & $\checkmark$ & $\checkmark$ & $\checkmark$ & - & - \\
\hline Side-bending & 1 & 71 & $\checkmark$ & - & - & $\checkmark$ & $18.8-62.2$ & - & - & $\checkmark$ & - & - \\
\hline
\end{tabular}

maint. maintenance treatment, No. number.

${ }^{a}$ Only study participants who performed the assessments were counted.

bIncluding other cancer diagnoses and diagnoses that were not clearly specified.

If evaluated in a childhood cancer population.

\begin{tabular}{|c|c|c|c|c|c|c|c|c|c|c|c|c|}
\hline Assessment & $\begin{array}{l}\text { No. of } \\
\text { studies }\end{array}$ & $\begin{array}{l}\text { Total } \\
\text { sample } \\
\text { size }^{\mathrm{a}}\end{array}$ & \multicolumn{4}{|c|}{ Type of cancer } & $\begin{array}{l}\text { Age in } \\
\text { years } \\
\text { (range) }\end{array}$ & \multicolumn{3}{|c|}{$\begin{array}{l}\text { Phases of } \\
\text { treatment }\end{array}$} & Validity $^{c}$ & Reliability \\
\hline TUG $3 \mathrm{~m}$ & 25 & 4,283 & $\checkmark$ & $\checkmark$ & $\checkmark$ & $\checkmark$ & $3.5-64$ & $\checkmark$ & $\checkmark$ & $\checkmark$ & $\checkmark$ & $\checkmark$ \\
\hline $\begin{array}{l}\text { Floor to stand } \\
\text { performance }\end{array}$ & 1 & 62 & $\checkmark$ & - & - & - & $1-22$ & $\checkmark$ & - & - & - & - \\
\hline $\begin{array}{l}\text { Stand up from } \\
\text { bed rest exam }\end{array}$ & 1 & 11 & $\checkmark$ & - & - & $\checkmark$ & $3.5-15$ & $\checkmark$ & - & - & - & - \\
\hline
\end{tabular}

assessing physical or functional performance evaluated cardiorespiratory fitness as an outcome. The 68 studies testing for cardiorespiratory fitness using seven different assessment tools highlight a high homogeneity in the choice of methods. Flexibility was also frequently examined with very uniform assessments. In contrast, muscle strength tests and motor performance batteries have also been evaluated in a high number of studies (57 resp. 49), although with enormous variation in assessment tools. Therefore, the idea of harmonizing physical and functional performance assessments arises to improve comparability of study results. However, harmonization does not seem appropriate nor reasonable across all pediatric cancer types, age groups, treatment phases, and research questions.

Speed as a physical performance measure has rarely been evaluated. It can be hypothesized that speed, assessed via shuttle run or other running tests, is difficult to assess during cancer treatment, because children are in a reduced overall condition during cancer treatment. In addition, the health benefits of speed for children and young people appear to be less prominent in the literature than cardiorespiratory fitness and muscle strength ${ }^{167}$ and are therefore less focused in children with and after cancer.

In terms of treatment phase, most studies (66\%) have been conducted after cessation of cancer therapy with childhood cancer survivors. The evaluation of persistent physical limitations is of great importance, as they may be limiting to working ability and participation. ${ }^{168}$ Nevertheless, a continuous monitoring of physical performance should be carried out from the time of diagnosis in order to detect physical limitations at an early stage and prevent further deterioration in a sense of early rehabilitation. At the same time, assessment of physical performance from diagnosis onward is important to determine the need for structured exercise. However, since physical fitness, medical side effects, and motivation vary considerably over the course of the therapy, and are dependent on age, diagnoses, and cancer stage, assessment tools evaluating physical performance and function in children with cancer have to fulfill many requirements. To be feasible and safe, different assessments might be chosen according to different groups of patients.

In terms of sample size, eight tests should be highlighted as they were performed by more than 1000 children each, namely grip and isokinetic dynamometry (muscle strength), 6MWT and maximum CPET (cardiorespiratory fitness), goniometry and sit and reach (flexibility), TUG 3 (functional mobility), and SOT (balance). Of those, the 6MWT $(n=6180)$, grip strength $(n=4451)$, and TUG $3 \mathrm{~m}(n=4283)$ were the tests with the greatest number of participants. This fact suggests that those outcomes are of specific interest in pediatric oncology as scientists and clinicians seem specifically concerned about their patients' ability to perform everyday activities, since functional mobility as well as walking capacity measured with the 6MWT are considered important prerequisites to perform physically activities of everyday life. ${ }^{46,169,170}$

Concerning the motor test batteries, geographical differences are noticeable. It can be assumed that countries use tests for which reference values of healthy kindergarten and schoolchildren are available. Especially for younger children motor performance test batteries seem to be appropriate to generate an overview of age-related motor development in comparison with age-related reference values. However, generating a database with reference values for children during and after cancer 


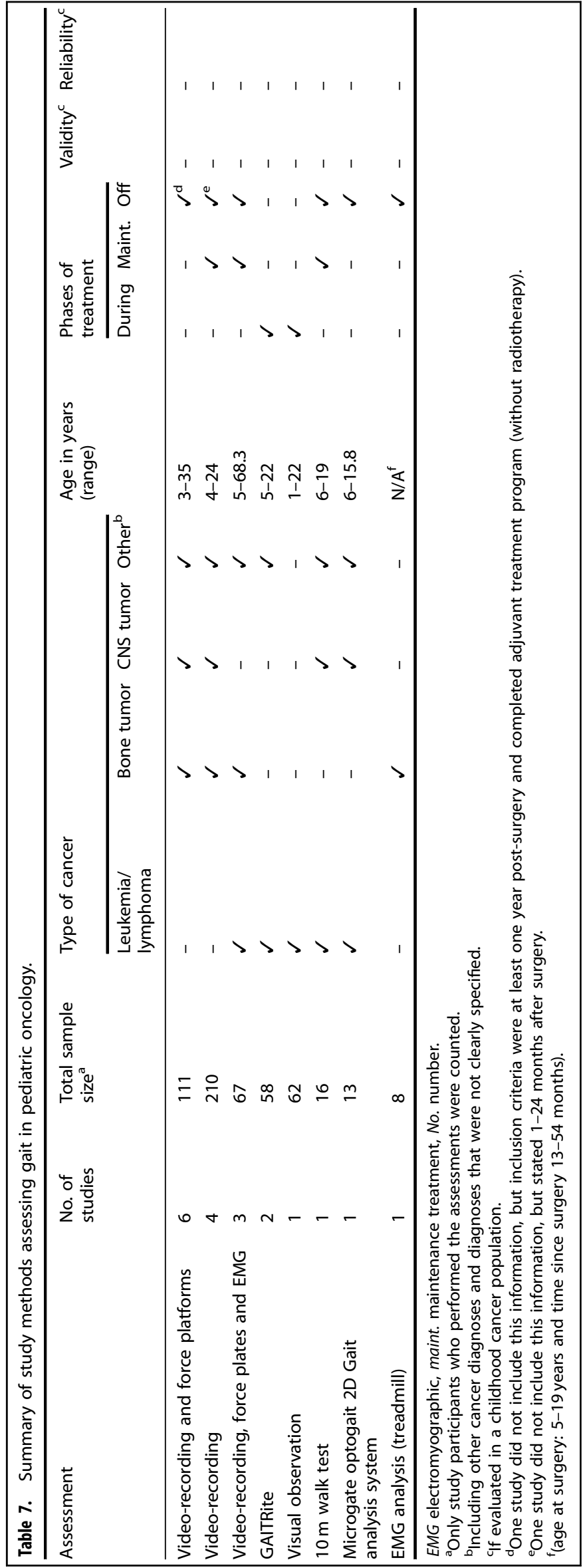

treatment could be helpful to evaluate skills in the context of cancer treatment.

Measurement properties such as validity or reliability of assessments are rarely available for the population of pediatric cancer patients or survivors. With reference to the period covered by this search, only the 9MWT, TUG $3 \mathrm{~m}$, GMFM, and GMFM-ALL have been tested for validity and reliability, while others (hand held dynamometry, isokinetic dynamometry, repetition maximum test, shuttle run, gonimetry, TUDS, TUG $10 \mathrm{~m}$, and UQAC-UQAM test battery) have been tested for reliability within this population. In addition, it might be useful to examine the quality criteria for children with chronic conditions in general since various chronic health conditions are present during/after pediatric cancer treatment ranging from endocrinological to orthopedic and psychosocial problems. ${ }^{171}$ Moreover, information on quality criteria assessed with healthy children may also be helpful while choosing appropriate assessments. Cooperation of interdisciplinary professional societies and scientists could contribute to a joint evaluation of the quality criteria for chronically ill and disabled children.

Overall, due to the variety of assessments used and the small cohorts often found in childhood cancer studies, the significance of studies on physical and functional performance is very limited. Furthermore, it is hypothesized that children with severe physical limitations have been excluded from many tests that have originally been developed for healthy children.

Limitations and strength

The strength of this article lies in the comprehensive research, systematic elaboration, and overview of all methods used to test physical performance in the context of pediatric oncology. The inclusion of interventional as well as observational studies allows a complete listing and a clear focus on the assessment tools. Although the lack of a rating and recommendation of the assessments seems to be a weakness, this evaluation was deliberately avoided. Recommendations based on single studies with large sample sizes, personal experiences, or geographical preferences appear inappropriate, as the objective presentation of the assessments were the primary aim. Instead, the results enable researchers and practitioners to select methods from this paper that correspond to their individual research questions or everyday practice and inform researchers about urgent research questions. The elaboration of recommendations and contraindications for the individual therapy phases, cancer types, and study settings as well as the evaluation of the quality criteria in the target group of children with cancer should be the subject of further research in the context of an international consensus. Methodological limitations include that no distinction has been made between diagnosis subgroups (i.e. myeloid and lymphoblastic leukemia) due to lack of detailed descriptions within studies included. The reader should be aware that the frequency with which an assessment is used does not allow any direct conclusions to be drawn about the quality and suitability of the assessment. Rather, the publication date of the assessment, national availability, and translations, as well as material and costs may also have an influence.

\section{Clinical implication}

This systematic review identified 149 studies assessing any category of physical or functional performance in childhood cancer patients or survivors. However, the evidence for the effectiveness of interventions to improve aspects of physical performance is very limited. ${ }^{9,172}$ This might be related to the methodological quality of intervention studies. However, using standardized tools to assess physical and functional performance in defined subgroups of pediatric cancer patients and survivors (i.e. children with ALL during treatment) would enable metaanalyses of single cohorts and overall improve the significance of 
Physical and functional performance assessment in pediatric oncology: a...

R Söntgerath et al.

Table 8. Summary of study methods assessing motor performance in test batteries in pediatric oncology.

\begin{tabular}{|c|c|c|c|c|c|c|c|c|c|c|c|c|}
\hline \multirow[t]{2}{*}{ Assessment } & \multirow[t]{2}{*}{$\begin{array}{l}\text { No. of } \\
\text { studies }\end{array}$} & \multirow{2}{*}{$\begin{array}{l}\text { Total } \\
\text { sample } \\
\text { size }^{\mathrm{a}}\end{array}$} & \multicolumn{4}{|c|}{ Type of cancer } & \multirow{2}{*}{$\begin{array}{l}\text { Age in } \\
\text { years } \\
\text { (range) }\end{array}$} & \multicolumn{3}{|c|}{$\begin{array}{l}\text { Phases of } \\
\text { treatment }\end{array}$} & \multirow[t]{2}{*}{ Validity $^{c}$} & \multirow[t]{2}{*}{ Reliability $^{c}$} \\
\hline & & & $\begin{array}{l}\text { Leukemia/ } \\
\text { lymphoma }\end{array}$ & Bone tumors & CNS tumors & Other $^{\mathrm{b}}$ & & active & Maint. & Off & & \\
\hline BOT-2 & 10 & 327 & $\checkmark$ & $\checkmark$ & $\checkmark$ & $\checkmark$ & $4-22$ & $\checkmark$ & - & $\checkmark$ & - & - \\
\hline BOT-2 SF & 6 & 384 & $\checkmark$ & - & - & - & $4-18$ & $\checkmark$ & $\checkmark$ & $\checkmark$ & - & - \\
\hline$m-A B C$ & 5 & 283 & $\checkmark$ & - & - & $\checkmark$ & $4.0-19.3$ & $\checkmark$ & - & $\checkmark$ & - & - \\
\hline$m-A B C 2$ & 5 & 124 & $\checkmark$ & $\checkmark$ & - & $\checkmark$ & $3-18.7$ & $\checkmark$ & - & $\checkmark$ & - & - \\
\hline FMA & 4 & 276 & - & $\checkmark$ & - & $\checkmark$ & $10.4-42.4$ & $\checkmark$ & - & $\checkmark$ & - & - \\
\hline MOON-test & 4 & 141 & $\checkmark$ & $\checkmark$ & $\checkmark$ & $\checkmark$ & $4-23$ & $\checkmark$ & $\checkmark$ & $\checkmark$ & - & - \\
\hline DMT 6-18 & 4 & 70 & $\checkmark$ & $\checkmark$ & $\checkmark$ & $\checkmark$ & $6-17$ & - & $\checkmark$ & $\checkmark$ & - & - \\
\hline GMFM & 4 & 62 & $\checkmark$ & - & - & - & $2-14.6$ & $\checkmark$ & $\checkmark$ & $\checkmark$ & $\checkmark$ & $\checkmark$ \\
\hline FMS & 1 & 26 & $\checkmark$ & - & $\checkmark$ & $\checkmark$ & $5-8$ & - & - & $\checkmark$ & - & - \\
\hline GMFM - ALL & 1 & 20 & $\checkmark$ & - & - & - & $2.8-15.9$ & $\checkmark$ & $\checkmark$ & - & $\checkmark$ & $\checkmark$ \\
\hline $\begin{array}{l}\text { UQAC-UQAM Test } \\
\text { Battery }\end{array}$ & 1 & 20 & $\checkmark$ & - & - & - & $9-11$ & - & - & $\checkmark$ & $\checkmark$ & - \\
\hline $\begin{array}{l}\text { Physical fitness battery } \\
\text { test adapted by alpha- } \\
\text { fitness-test-battery }\end{array}$ & 1 & 18 & $\checkmark$ & - & - & - & $\begin{array}{l}7.55 \pm \\
2.43\end{array}$ & - & - & $\checkmark$ & - & - \\
\hline FITNESSGRAM & 1 & 10 & $\checkmark$ & - & $\checkmark$ & $\checkmark$ & $14.0-18.0$ & $\checkmark$ & - & $\checkmark$ & - & - \\
\hline
\end{tabular}

BOT Bruininks-Oseretsky Test, SF short form, $m$-ABC Movement Assessment Battery for Children, BOTMP Bruininks-Oseretsky Test of Motor Proficiency, FMA functional mobility assessment, MOON motor performance in pediatric oncology, DMT Deutscher Motorik Test, GMFM gross motor function measure, MOT Motoriktest für Kinder, FMS fundamental movement skills test battery, ALL acute lymphoblastic leukemia, UQAC-UQAM University of Québec in ChicoutimiUniversity of Québec in Montreal, maint. maintenance treatment, No. number.

a Only study participants who performed the assessments were counted.

b Including other cancer diagnoses and diagnoses that were not clearly specified.

If evaluated in a childhood cancer population.

Table 9. Summary of the main findings.

Main findings are...

1. Physical function and performance were mostly evaluated after medical treatment.

2. Leukemia patients formed the most examined group while solid tumors were less studied.

3. Cardiorespiratory fitness and muscle strength were the physical outcomes of main interest.

4. Assessments with the highest number of participants were

- 6 MWT ( $n=6180$ in 26 studies)

- Grip strength ( $n=4451$ in 27 studies)

- TUG $3 \mathrm{~m}$ ( $n=4283$ in 25 studies).

5. Most assessments have not been evaluated for validity and reliability in pediatric cancer populations.

6MWT 6-minute walk test, TUG timed up and go test.

studies. Apart from clinical research, clinicians, exercise physiologists, and physiotherapists may choose assessment tools presented here with regard to their individual needs and objectives.

Future research

Future research should focus on evaluating the measurement properties of methods in pediatric cancer populations and children with other chronic diseases. In addition, building an international recommendation statement for assessments in smaller subgroups of pediatric cancer patients and survivors could be a valuable contribution to the current knowledge.
Another important step is to generate a database with standard values of children and adolescents suffering from cancer. This could help to compare measures from research and clinical work with children with other chronic conditions, identify impairments and react with early interventions to improve cancer treatment and decrease negative side effects. To expand existing knowledge about leukemia patients to other diagnoses, cancer types like neuroblastoma, retinoblastoma, renal tumors, or soft tissue sarcoma should be tested for physical performance limitations to evaluate their special needs. Furthermore, acute and maintenance treatment phases are less studied but might be of special 
interest to prevent physical performance deconditioning. And finally, since survivors of childhood cancer can experience very heterogeneous late sequelae, a transferability of the test applications to children with heart or lung diseases, metabolic diseases, or other chronic conditions is conceivable and should be verified in future research projects.

\section{ACKNOWLEDGEMENTS}

The authors are a subgroup of the Network ActiveOncoKids. This network is committed to promoting physical activity for children and young people with cancer. The network members had the opportunity to give feedback and contribute ideas during meetings and were thus partly involved in the development of this work. This work was in parts supported by the Deutsche Forschungsgemeinschaft (DFG). The DFG had no role in the design and conduct of the study.

\section{AUTHOR CONTRIBUTIONS}

R.S., J.D., and M.G. conceptualized and designed the study, collected data, carried out the analyses, interpreted the data, drafted the initial manuscript, and revised the manuscript. S.R., T.-C.W., and C.C.-V. participated in data collection and data extraction and reviewed and revised the manuscript. S.V.K., K.G.E., V.O., C.S.R., A.S.M., S.S., A.-M.T., J.W., and P.W. participated in the conceptualization of the study, provided critical feedback throughout data collection and extraction, and critically reviewed the manuscript for important intellectual content. All authors approved the final manuscript as submitted and agree to be accountable for all aspects of the work.

\section{FUNDING}

Open Access funding enabled and organized by Projekt DEAL.

\section{ADDITIONAL INFORMATION}

Supplementary information The online version contains supplementary material available at https://doi.org/10.1038/s41390-021-01523-5.

Competing interests: The authors declare no competing interests.

Consent statement: No patient consent required.

Publisher's note Springer Nature remains neutral with regard to jurisdictional claims in published maps and institutional affiliations.

\section{REFERENCES}

1. Janssen, I. L. A. G. Systematic review of the health benefits of physical activity and fitness in school-aged children and youth. Int. J. Behav. Nutr. Phys. Act. 7, 40 (2010).

2. Ness, K. K. et al. Physical performance limitations in the Childhood Cancer Survivor Study cohort. J. Clin. Oncol. 27, 2382-2389 (2009).

3. Götte, M., Kesting, S. V., Winter, C. C., Rosenbaum, D. \& Boos, J. Motor performance in children and adolescents with cancer at the end of acute treatment phase. Eur. J. Pediatr. 174, 791-799 (2015).

4. Söntgerath, R. \& Eckert, K. Impairments of lower extremity muscle strength and balance in childhood cancer patients and survivors: a systematic review. Pediatr. Hematol. Oncol. 32, 585-612 (2015).

5. Götte, M., Taraks, S. \& Boos, J. Sports in pediatric oncology: the role(s) of physical activity for children with cancer. J. Pediatr. Hematol. Oncol. 36, 85-90 (2014).

6. Deisenroth, A. et al. Muscle strength and quality of life in patients with childhood cancer at early phase of primary treatment. Pediatr. Hematol. Oncol. 33, 393-407 (2016).

7. Phillips, N. S. et al. Physical fitness and neurocognitive outcomes in adult survivors of childhood acute lymphoblastic leukemia: a report from the St. Jude Lifetime cohort. Cancer 126, 640-648 (2020).

8. Ness, K. K. et al. The impact of limitations in physical, executive, and emotional function on health-related quality of life among adult survivors of childhood cancer: a report from the Childhood Cancer Survivor Study. Arch. Phys. Med. Rehabil. 89, 128-136 (2008).

9. Braam, K. I. et al. Physical exercise training interventions for children and young adults during and after treatment for childhood cancer. Cochrane Database Syst. Rev. 3, CD008796 (2016)
10. Senn-Malashonak, A. et al. Psychophysical effects of an exercise therapy during pediatric stem cell transplantation: a randomized controlled trial. Bone Marrow Transplant. 54, 1827-1835 (2019).

11. Stössel, S. et al. Benefits of exercise training for children and adolescents undergoing cancer treatment: results from the randomized controlled MUCKI Trial. Front. Pediatr. 8, 243 (2020).

12. Grimshaw, S. L., Taylor, N. F., Mechinaud, F. \& Shields, N. Assessment of physical function in children with cancer: a systematic review. Pediatr. Blood Cancer 65, e27369 (2018)

13. Shank, J. et al. Evaluation tools for physical activity programs for childhood cancer: a scoping review. J. Pediatr. Oncol. Nurs. 37, 163-179 (2020).

14. American College of Sports Medicine. ACSM's Guidelines for Exercise Testing and Prescription 10th edn. (Wolters Kluwer, 2017).

15. Moher, D., Liberati, A., Tetzlaff, J. \& Altman, D. G. Preferred reporting items for systematic reviews and meta-analyses: the PRISMA statement. BMJ 339, b2535 (2009).

16. Wacker, K., Tanner, L., Ovans, J., Mason, J. \& Gilchrist, L. Improving functional mobility in children and adolescents undergoing treatment for non-central nervous system cancers: a systematic review. PM R 9, S385-S397 (2017).

17. Beulertz, J. et al. Limitations in ankle dorsiflexion range of motion, gait, and walking efficiency in childhood cancer survivors. Cancer Nurs. 39, 117-124 (2016).

18. Keiser, T. et al. Short-term consequences of pediatric anti-cancer treatment regarding blood pressure, motor performance, physical activity and reintegration into sports structures. Front. Pediatr. 8, 463 (2020).

19. Rueegg, C. S. et al. Physical performance limitations in adolescent and adult survivors of childhood cancer and their siblings. PLoS ONE 7, e47944 (2012).

20. Akyay, A., Olcay, L., Sezer, N. \& Atay Sönmez, C. Muscle strength, motor performance, cardiac and muscle biomarkers in detection of muscle side effects during and after acute lymphoblastic leukemia treatment in children. J. Pediatr. Hematol. Oncol. 36, 594-598 (2014).

21. Bastian, A. J., Mink, J. W., Kaufman, B. A. \& Thach, W. T. Posterior vermal split syndrome. Ann. Neurol. 44, 601-610 (1998).

22. Bell, W. et al. Perception of effort at low and moderate intensity exercise in survivors of childhood acute lymphoblastic leukaemia. Ann. Hum. Biol. 33, 357-371 (2006).

23. Benedetti, M. G. et al. How much clinical and functional impairment do children treated with knee rotationplasty experience in adulthood? Clin. Orthop. Relat. Res. 474, 995-1004 (2016).

24. Beulertz, J., Bloch, W., Prokop, A. \& Baumann, F. T. Specific deficit analyses in motor performance and quality of life of pediatric cancer patients-a crosssectional pilot study. Pediatr. Hematol. Oncol. 30, 336-347 (2013).

25. Beulertz, J. et al. Limitations in ankle dorsiflexion range of motion, gait, and walking efficiency in childhood cancer survivors. Cancer Nurs. 39, 117-124 (2016).

26. Beulertz, J. et al. Effects of a 6-month, group-based, therapeutic exercise program for childhood cancer outpatients on motor performance, level of activity, and quality of life. Pediatr. Blood Cancer 63, 127-132 (2016).

27. Bianco, A. et al. Evaluation of fitness levels of children with a diagnosis of acute leukemia and lymphoma after completion of chemotherapy and autologous hematopoietic stem cell transplantation. Cancer Med. 3, 385-389 (2014).

28. Black, P., Gutjahr, P. \& Stopfkuchen, H. Physical performance in long-term survivors of acute leukaemia in childhood. Eur. J. Pediatr. 157, 464-467 (1998).

29. Braam, K. I. et al. Cardiorespiratory fitness and physical activity in children with cancer. Support Care Cancer 24, 2259-2268 (2016).

30. Braam, K. I. et al. Effects of a combined physical and psychosocial training for children with cancer: a randomized controlled trial. BMC Cancer 18, 1289 (2018).

31. Braam, K. I. et al. Application of the steep ramp test for aerobic fitness testing in children with cancer. Eur. J. Phys. Rehabil. Med. 51, 547-555 (2015).

32. Brinkman, T. M. et al. Attainment of functional and social independence in adult survivors of pediatric cns tumors: a report from the St Jude Lifetime Cohort Study. J. Clin. Oncol. 36, 2762-2769 (2018).

33. Carty, C. P., Bennett, M. B., Dickinson, I. C. \& Steadman, P. Assessment of kinematic and kinetic patterns following limb salvage procedures for bone sarcoma. Gait Posture 30, 547-551 (2009).

34. Carty, C. P., Dickinson, I. C., Watts, M. C., Crawford, R. W. \& Steadman, P. Impairment and disability following limb salvage procedures for bone sarcoma. Knee 16, 405-408 (2009).

35. Corr, A. M. et al. Feasibility and functional outcomes of children and adolescents undergoing preoperative chemotherapy prior to a limb-sparing procedure or amputation. Rehabil. Oncol. 35, 38-45 (2017).

36. Cortés-Reyes, É., Escobar-Zabala, P. \& González-García, L. The effect of gamebased exercise on infant acute lymphocytic leukaemia patients. Rev. Fac. Med. 61, 349-355 (2013). 
37. Cox, C. L. et al. Modifying bone mineral density, physical function, and quality of life in children with acute lymphoblastic leukemia. Pediatr. Blood Cancer https:// doi.org/10.1002/pbc.26929 (2018).

38. Däggelmann, J. et al. Einfluss einer vierwöchigen familienorientierten Rehabilitation auf die motorische Leistungsfähigkeit, Lebensqualität und Fatigue bei krebskranken Kindern und gesunden Geschwistern. Rehabilitation (Stuttg.). 56, 119-126 (2017)

39. Davis, E. E., Pitchford, N. J., Jaspan, T., McArthur, D. \& Walker, D. Development of cognitive and motor function following cerebellar tumour injury sustained in early childhood. Cortex 46, 919-932 (2010).

40. De Caro, E. et al. Exercise capacity in apparently healthy survivors of cancer. Arch. Dis. Child. 91, 47-51 (2006).

41. DeFeo, B. M. et al. Long-term functional outcomes among childhood survivors of cancer who have a history of osteonecrosis. Phys. Ther. 100, 509-522 (2020).

42. Dubnov-Raz, G. et al. Changes in fitness are associated with changes in body composition and bone health in children after cancer. Acta Paediatr. 104, 1055-1061 (2015).

43. Ehrhardt, M. J. et al. Late outcomes of adult survivors of childhood non-Hodgkin lymphoma: a report from the St. Jude Lifetime Cohort Study. Pediatr. Blood Cancer https://doi.org/10.1002/pbc.26338 (2017).

44. Esbenshade, A. J. et al. Feasibility and initial effectiveness of home exercise during maintenance therapy for childhood acute lymphoblastic leukemia. Pediatr. Phys. Ther. 26, 301-307 (2014).

45. Fiorillo, A., Rinaldi, M. \& Foggia, L. Gait analysis in children treated by surgery followed by adjuvant therapy for posterior fossa tumors. Acta Neurol. Belg. 110, 306-310 (2010).

46. Fiuza-Luces, C. et al. Exercise intervention in pediatric patients with solid tumors: The Physical Activity in Pediatric Cancer Trial. Med. Sci. Sports Exerc. 49, 223-230 (2017)

47. Fuchs, B., Kotajarvi, B. R., Kaufman, K. R. \& Sim, F. H. Functional outcome of patients with rotationplasty about the knee. Clin. Orthop. Relat. Res. 52-58, https://doi.org/10.1097/01.blo.0000093896.12372.c1 (2003).

48. Galea, V., Wright, M. J. \& Barr, R. D. Measurement of balance in survivors of acute lymphoblastic leukemia in childhood. Gait Posture 19, 1-10 (2004).

49. Gerber, L. H. et al. Functional outcomes and life satisfaction in long-term survivors of pediatric sarcomas. Arch. Phys. Med. Rehabil. 87, 1611-1617 (2006).

50. Gilchrist, L. \& Tanner, L. Gait patterns in children with cancer and vincristine neuropathy. Pediatr. Phys. Ther. 28, 16-22 (2016).

51. Gilchrist, L. S. \& Tanner, L. R. Short-term recovery of balance control: association with chemotherapy-induced peripheral neuropathy in pediatric oncology. Pediatr. Phys. Ther. 30, 119-124 (2018).

52. Gilliam, M. B. et al. A pilot study evaluation of a web-based token economy to increase adherence with a community-based exercise intervention in child and adolescent cancer survivors. Rehabil. Oncol. 29, 16-22 (2011).

53. Ginsberg, J. P. et al. A comparative analysis of functional outcomes in adolescents and young adults with lower-extremity bone sarcoma. Pediatr. Blood Cancer 49, 964-969 (2007).

54. Gohar, S. F., Comito, M., Price, J. \& Marchese, V. Feasibility and parent satisfaction of a physical therapy intervention program for children with acute lymphoblastic leukemia in the first 6 months of medical treatment. Pediatr. Blood Cancer 56, 799-804 (2011)

55. Götte, M. et al. MOON-test-determination of motor performance in the pediatric oncology. Klin. Padiatr. 225, 133-137 (2013).

56. Götte, M., Kesting, S. V., Gerss, J., Rosenbaum, D. \& Boos, J. Feasibility and effects of a home-based intervention using activity trackers on achievement of individual goals, quality of life and motor performance in patients with paediatric cancer. BMJ Open Sport Exerc. Med. 4, e000322 (2018).

57. Hamari, L. et al. The effect of an active video game intervention on physical activity, motor performance, and fatigue in children with cancer: a randomized controlled trial. BMC Res. Notes 12, 784 (2019).

58. Harten, G. et al. Slight impairment of psychomotor skills in children after treatment of acute lymphoblastic leukemia. Eur. J. Pediatr. 142, 189-197 (1984).

59. Hartman, A. et al. A randomized trial investigating an exercise program to prevent reduction of bone mineral density and impairment of motor performance during treatment for childhood acute lymphoblastic leukemia. Pediatr. Blood Cancer 53, 64-71 (2009).

60. Hartman, A. et al. Polymorphisms in genes involved in vincristine pharmacokinetics or pharmacodynamics are not related to impaired motor performance in children with leukemia. Leuk. Res. 34, 154-159 (2010).

61. Hartman, A., Hop, W., Takken, T., Pieters, R. \& van den Heuvel-Eibrink, M. Motor performance and functional exercise capacity in survivors of pediatric acute lymphoblastic leukemia. Pediatr. Blood Cancer 60, 494-499 (2013).

62. Hartman, A. et al. Health-related fitness in very long-term survivors of childhood cancer: a cross-sectional study. Pediatr. Blood Cancer. https://doi.org/10.1002/ pbc.26907 (2018)
63. Hartman, A., van den Bos, C., Stijnen, T. \& Pieters, R. Decrease in motor performance in children with cancer is independent of the cumulative dose of vincristine. Cancer 106, 1395-1401 (2006).

64. Hartman, A., van den Bos, C., Stijnen, T. \& Pieters, R. Decrease in peripheral muscle strength and ankle dorsiflexion as long-term side effects of treatment for childhood cancer. Pediatr. Blood Cancer 50, 833-837 (2008).

65. Hauser, M., Gibson, B. \& Wilson, N. Diagnosis of anthracycline-induced late cardiomyopathy by exercise-spiroergometry and stress-echocardiography. Eur. J. Pediatr. 160, 607-610 (2001).

66. Henderson, E. R. et al. Outcome of lower-limb preservation with an expandable endoprosthesis after bone tumor resection in children. J. Bone Jt. Surg. Am. 94, 537-547 (2012).

67. Hillmann, A. et al. Rotationsplasty Type B Illa according to Winkelmann: electromyography and gait analysis. Clin. Orthop. Relat. Res. 384, 224-231 (2001).

68. Hillmann, A. et al. Electromyographic and gait analysis of forty-three patients after rotationsplasty. J. Bone Jt. Surg. Am. 82, 187-196 (2000).

69. Hoffman, M. C. et al. Deficits in physical function among young childhood cancer survivors. J. Clin. Oncol. 31, 2799-2805 (2013).

70. Hogarty, A. N. et al. Longitudinal evaluation of cardiopulmonary performance during exercise after bone marrow transplantation in children. J. Pediatr. 136, 311-317 (2000).

71. Hovi, L., Era, P., Rautonen, J. \& Siimes, M. A. Impaired muscle strength in female adolescents and young adults surviving leukemia in childhood. Cancer 72, 276-281 (1993).

72. Hovi, L. et al. Suboptimal long-term physical performance in children and young adults after pediatric allo-SCT. Bone Marrow Transplant. 45, 738-745 (2010).

73. Howell, C. R. et al. Randomized web-based physical activity intervention in adolescent survivors of childhood cancer. Pediatr. Blood Cancer 65, e27216 (2018).

74. Hung, S. H. et al. Associating physical activity levels with motor performance and physical function in childhood survivors of acute lymphoblastic leukemia. Physiother. Can. 69, 57-64 (2017).

75. Järvelä, L. S. et al. Physical activity and fitness in adolescent and young adult long-term survivors of childhood acute lymphoblastic leukaemia. J. Cancer Surviv. 4, 339-345 (2010).

76. Jenney, M. E. M., Faragher, E. B., Morris Jones, P. H. \& Woodcock, A. Lung function and exercise capacity in survivors of childhood leukaemia. Med. Pediatr. Oncol. 24, 222-230 (1995).

77. Johnson, D. et al. Cardiovascular responses to dynamic submaximal exercise in children previously treated with anthracycline. Am. Heart J. 133, 169-173 (1997).

78. Joyce, E. D. et al. Association of muscle strength and bone mineral density in adult survivors of childhood acute lymphoblastic leukemia. Arch. Phys. Med. Rehabil. 92, 873-879 (2011)

79. Kabak, V. Y., Duger, T. \& Uckan Cetinkaya, D. Investigation of the effects of an exercise program on physical functions and activities of daily life in pediatric hematopoietic stem cell transplantation. Pediatr. Blood Cancer 63, 1643-1648 (2016).

80. Kandula, T. et al. Chemotherapy-induced peripheral neuropathy in long-term survivors of childhood cancer: clinical, neurophysiological, functional, and patient-reported outcomes. JAMA Neurol. 75, 980-988 (2018).

81. Keats, M. R. \& Culos-Reed, S. N. A community-based physical activity program for adolescents with cancer (Project TREK). J. Pediatr. Hematol. Oncol. 30, 272-280 (2008).

82. Kesting, S. V., Götte, M., Seidel, C. C., Rosenbaum, D. \& Boos, J. Motor performance after treatment for pediatric bone tumors. J. Pediatr. Hematol. Oncol. 37, 509-514 (2015).

83. Konczak, J., Schoch, B., Dimitrova, A., Gizewski, E. \& Timmann, D. Functional recovery of children and adolescents after cerebellar tumour resection. Brain 128, 1428-1441 (2005)

84. Lam, K. K. W. et al. An integrated experiential training programme with coaching to promote physical activity, and reduce fatigue among children with cancer: a randomised controlled trial. Patient Educ. Couns. 101, 1947-1956 (2018).

85. Leone, $M$. et al. Assessment of gross motor skills and phenotype profile in children 9-11 years of age in survivors of acute lymphoblastic leukemia. Pediatr. Blood Cancer 61, 46-52 (2014).

86. Long, T. M. et al. Fitness, body composition and vascular health in adolescent and young adult survivors of paediatric brain cancer and cranial radiotherapy. Int. J. Adolesc. Med. Health. https://doi.org/10.1515/ijamh-2017-0082 (2017).

87. Long, T. M. et al. Exercise training improves vascular function and secondary health measures in survivors of pediatric oncology related cerebral insult. PLOS ONE 13, e0201449 (2018)

88. Luca de, C. R. et al. Gross and fine motor skills in children treated for acute lymphoblastic leukaemia. Dev. Neurorehabil. 16, 180-187 (2013).

89. Malicka, I., Kowaluk, A. \& Woźniewski M. Does daily physical activity level determine the physical efficiency of children after treatment of leukemia? Int. J. Environ. Res. Public Health https://doi.org/10.3390/ijerph17010307 (2020). 
90. Malicka, l. et al. Physical fitness of school-age children after cancer treatment. Int. J. Environ. Res. Public Health. https://doi.org/10.3390/ijerph16081436 (2019).

91. Manchola-González, J. D. et al. Effects of a home-exercise programme in childhood survivors of acute lymphoblastic leukaemia on physical fitness and physical functioning: results of a randomised clinical trial. Support Care Cancer https://doi.org/10.1007/s00520-019-05131-2 (2019).

92. Marchese, V. G., Chiarello, L. A. \& Lange, B. J. Effects of physical therapy intervention for children with acute lymphoblastic leukemia. Pediatr. Blood Cancer 42, 127-133 (2004a).

93. Marchese, V. G., Ogle, S., Womer, R. B., Dormans, J. \& Ginsberg, J. P. An examination of outcome measures to assess functional mobility in childhood survivors of osteosarcoma. Pediatr. Blood Cancer 42, 41-45 (2004b).

94. Marchese, V. G. et al. Assessing functional mobility in survivors of lowerextremity sarcoma: reliability and validity of a new assessment tool. Pediatr. Blood Cancer 49, 183-189 (2007).

95. Marchese, V. G. et al. Relationships among range of motion, functional mobility, and quality of life in children and adolescents after limb-sparing surgery for lower-extremity sarcoma. Pediatr. Phys. Ther. 18, 238-244 (2006).

96. Marchese, V. G., Chiarello, L. A. \& Lange, B. J. Strength and functional mobility in children with acute lymphoblastic leukemia. Med. Pediatr. Oncol. 40, 230-232 (2003).

97. Marchese, V. G. et al. Relationships among severity of osteonecrosis, pain, range of motion, and functional mobility in children, adolescents, and young adults with acute lymphoblastic leukemia. Phys. Ther. 88, 341-350 (2008).

98. Matthys, D. et al. Gender difference in aerobic capacity in adolescents after cure from malignant disease in childhood. Acta Paediatr. 82, 459-462 (1993).

99. McKenzie, D. C., Coutts, K. D., Rogers, P. C., Jespersen, D. K. \& Pretula, A. Aerobic and anaerobic capacities of children and adolescents successfully treated for solid tumors. Clin. Exerc. Physiol. 2, 39-42 (2000).

100. Mitchell, W. G. et al. Opsoclonus-ataxia caused by childhood neuroblastoma: developmental and neurologic sequelae. Pediatrics 109, 86-98 (2002).

101. Mitra, Varedi et al. Peripheral neuropathy, sensory processing, and balance in survivors of acute lymphoblastic leukemia. J. Clin. Oncol. 36, 2315-2322 (2018).

102. Moyer-Mileur, L. J., Ransdell, L. \& Bruggers, C. S. Fitness of children with standard-risk acute lymphoblastic leukemia during maintenance therapy: response to a home-based exercise and nutrition program. J. Pediatr. Hematol. Oncol. 31, 259-266 (2009).

103. Müller, C., Rosenbaum, D. \& Krauth, K. A. Prospective evaluation of postural control and gait in pediatric patients with cancer after a 4-week inpatient rehabilitation program. Am. J. Phys. Med. Rehabil. 96, 646-653 (2017).

104. Muratt, M. D. et al. Strength capacity in young patients who are receiving maintenance therapy for acute lymphoblastic leukemia: a case-control study. Clinics 66, 1277-1281 (2011).

105. Nama, N. et al. Vincristine-induced peripheral neurotoxicity: a prospective cohort. Pediatr. Hematol. Oncol. 37, 15-28 (2020).

106. Naumann, F. L. et al. Assessment of fundamental movement skills in childhood cancer patients. Pediatr. Blood Cancer 62, 2211-2215 (2015).

107. Ness, K. K. et al. Body composition, muscle strength deficits and mobility limitations in adult survivors of childhood acute lymphoblastic leukemia. Pediatr. Blood Cancer 49, 975-981 (2007).

108. Ness, K. K. et al. Energy balance and fitness in adult survivors of childhood acute lymphoblastic leukemia. Blood 125, 3411-3419 (2015a).

109. Ness, K. K. et al. Neuromuscular impairments in adult survivors of childhood acute lymphoblastic leukemia: associations with physical performance and chemotherapy doses. Cancer 118, 828-838 (2012).

110. Ness, K. K. et al. Chemotherapy-related neuropathic symptoms and functional impairment in adult survivors of extracranial solid tumors of childhood: results from the St. Jude Lifetime Cohort Study. Arch. Phys. Med. Rehabil. 94, 1451-1457 (2013).

111. Ness, K. K. et al. Skeletal, neuromuscular and fitness impairments among children with newly diagnosed acute lymphoblastic leukemia. Leuk. Lymphoma $\mathbf{5 6}$, 1004-1011 (2015).

112. Ness, K. K. et al. Physical performance limitations among adult survivors of childhood brain tumors. Cancer 116, 3034-3044 (2010).

113. Ness, K. K. et al. A comparison of function after limb salvage with non-invasive expandable or modular prostheses in children. Eur. J. Cancer 50, 3212-3220 (2014).

114. Nielsen, M. K. F. et al. Testing physical function in children undergoing intense cancer treatment-a RESPECT feasibility study. Pediatr. Blood Cancer 65, e27100 (2018).

115. Oschwald, V. et al. Limited walking abilities and impaired ankle dorsiflexion function in children after intense cancer treatment. Klin. Padiatr. 231, 142-149 (2019).

116. Oswald, K. A. \& Bo, J. Motor functioning and associated cognitive outcomes in pediatric survivors of acute lymphoblastic leukemia. Child Neuropsychol. 26, 597-611 (2020).
117. Ovans, J. A., Hooke, M. C., Bendel, A. E. \& Tanner, L. R. Physical therapist coaching to improve physical activity in children with brain tumors: a pilot study. Pediatr. Phys. Ther. 30, 310-317 (2018).

118. Papalia, H. et al. Metabolic response to exercise in childhood brain tumor survivors: a pilot controlled study. Pediatr. Blood Cancer 67, e28053 (2020).

119. Pesenti, S. et al. Knee function after limb salvage surgery for malignant bone tumor: comparison of megaprosthesis and distal femur allograft with epiphysis sparing. Int. Orthop. 42, 427-436 (2018).

120. Pihkala, J. et al. Cardiopulmonary evaluation of exercise tolerance after chest irradiation and anticancer chemotherapy in children and adolescents. Pediatrics 95, 722-726 (1995)

121. Piscione, P. J. et al. Exercise training improves physical function and fitness in long-term paediatric brain tumour survivors treated with cranial irradiation. Eur. J. Cancer 80, 63-72 (2017).

122. Piscione, P. J., Bouffet, E., Mabbott, D. J., Shams, I. \& Kulkarni, A. V. Physical functioning in pediatric survivors of childhood posterior fossa brain tumors. Neuro-Oncol. 16, 147-155 (2014).

123. Ramchandren, S. et al. Peripheral neuropathy in survivors of childhood acute lymphoblastic leukemia. J. Peripher. Nerv. Syst. 14, 184-189 (2009).

124. Reinders-Messelink, $\mathrm{H}$. et al. Motor performance of children during treatment for acute lymphoblastic leukemia. Med. Pediatr. Oncol. 33, 545-550 (1999).

125. Riggs, L. et al. Exercise training for neural recovery in a restricted sample of pediatric brain tumor survivors: a controlled clinical trial with crossover of training versus no training. Neuro-Oncol. 19, 440-450 (2017).

126. Rosenhagen, A. et al. Implementation of structured physical activity in the pediatric stem cell transplantation. Klin. Padiatr. 223, 147-151 (2011).

127. Sabel, M. et al. Active video gaming improves body coordination in survivors of childhood brain tumours. Disabil. Rehabil. 38, 2073-2084 (2016).

128. San Juan, A. F. et al. Functional capacity of children with leukemia. Int. J. Sports Med. 29, 163-167 (2008)

129. San Juan, A. F. et al. Benefits of intrahospital exercise training after pediatric bone marrow transplantation. Int. J. Sports Med. 29, 439-446 (2008).

130. San Juan, A. F. et al. Effects of an intrahospital exercise program intervention for children with leukemia. Med. Sci. Sports Exerc. 39, 13-21 (2007).

131. San Juan, A. F. et al. Early-phase adaptations to intrahospital training in strength and functional mobility of children with leukemia. J. Strength Cond. Res. 21, 173-177 (2007).

132. Schoch, B. et al. Impact of surgery and adjuvant therapy on balance function in children and adolescents with cerebellar tumors. Neuropediatrics 37, 350-358 (2006).

133. Schoch, B., Hogan, A., Gizewski, E. R., Timmann, D. \& Konczak, J. Balance control in sitting and standing in children and young adults with benign cerebellar tumors. Cerebellum 9, 324-335 (2010).

134. Schoenmakers MAGC et al. Muscle strength and functional ability in children during and after treatment for acute lymphoblastic leukemia or T-cell NonHodgkin lymphoma: a pilot study. Cancer Ther. 4, 241-248 (2006).

135. Segerer, F. J., Biko, J., Reiners, C., Wirth, C. \& Hebestreit, H. Exercise-induced hypoxemia in juvenile thyroid carcinoma with lung metastases. Pediatr. Exerc. Sci. 29, 361-370 (2017).

136. Shore, S. \& Shepard, R. J. Immune response to exercise in children treated for cancer. J. Sports Med. Phys. Fit. 39, 240-243 (1999).

137. Slater, M. E. et al. Physical activity, fitness, and cardiometabolic risk factors in adult survivors of childhood cancer with a history of hematopoietic cell transplantation. Biol. Blood Marrow Transplant. 21, 1278-1283 (2015).

138. Smith, W. A. et al. Measured versus self-reported physical function in adult survivors of childhood cancer. Med. Sci. Sports Exerc. 46, 211-218 (2014).

139. Smith, W. A. et al. Exercise training in childhood cancer survivors with subclinical cardiomyopathy who were treated with anthracyclines. Pediatr. Blood Cancer https://doi.org/10.1002/pbc.24850 (2013).

140. Steenhoff, J. R. M., Daanen, H. A. M. \& Taminiau, A. H. M. Functional analysis of patients who have had a modified Van Nes Rotationplasty. J. Bone Jt. Surg. Am. 75, 1451-1456 (1993).

141. Su, H.-L., Wu, L.-M., Chiou, S.-S., Lin, P.-C. \& Liao, Y.-M. Assessment of the effects of walking as an exercise intervention for children and adolescents with cancer: a feasibility study. Eur. J. Oncol. Nurs. 37, 29-34 (2018).

142. Syczewska, M., Dembowska-Bagińska, B., Perek-Polnik, M., Kalinowska, M. \& Perek, D. Postural sway in children and young adults, survivors of CNS tumours. Adv. Med. Sci. 53, 256-262 (2008).

143. Syczewska, M., Dembowska-Baginska, B., Perek-Polnik, M. \& Perek, D. Functional status of children after treatment for a malignant tumour of the CNS: a preliminary report. Gait Posture 23, 206-210 (2006).

144. Syczewska, M., Dembowska-Bagińska, B., Perek-Polnik, M., Kalinowska, M. \& Perek, D. Gait pathology assessed with Gillette Gait Index in patients after CNS tumour treatment. Gait Posture 32, 358-362 (2010). 
145. Takken, T. et al. Development, feasibility and efficacy of a community-based exercise training program in pediatric cancer survivors. Psychooncology 18, 440-448 (2009).

146. Talvensaari, K. K., Jämsen, A., Vanharanta, H. \& Lanning, M. Decreased isokinetic trunk muscle strength and performance in long-term survivors of childhood malignancies: correlation with hormonal defects. Arch. Phys. Med. Rehabil. 76, 983-988 (1995).

147. Tanir, M. K. \& Kuguoglu, S. Impact of exercise on lower activity levels in children with acute lymphoblastic leukemia: a randomized controlled trial from Turkey. Rehabil. Nurs. 38, 48-59 (2013).

148. Tanner, L., Sencer, S. \& Hooke, M. C. The Stoplight Program: a proactive physical therapy intervention for children with acute lymphoblastic leukemia. J. Pediatr. Oncol. Nurs. 34, 347-357 (2017).

149. Tanner, L. R. \& Hooke, M. C. Improving body function and minimizing activity limitations in pediatric leukemia survivors: the lasting impact of the Stoplight Program. Pediatr. Blood Cancer 66, e27596 (2019).

150. Tanner, L. R., Hooke, M. C., Hinshon, S. \& Hansen, C. R. Effect of an ankle foot orthosis intervention for children with non-central nervous system cancers: a pilot study. Pediatr. Phys. Ther. 27, 425-431 (2015).

151. Taskinen, M., Kurimo, M., Kanerva, J. \& Hovi, L. Physical performance of nontransplanted childhood ALL survivors is comparable to healthy controls. J. Pediatr. Hematol. Oncol. 35, 276-280 (2013).

152. Tay, C. G. et al. Vincristine-induced peripheral neuropathy in survivors of childhood acute lymphoblastic leukaemia. Pediatr. Blood Cancer https://doi.org/ 10.1002/pbc.26471 (2017)

153. Turner-Gomes, S. O. et al. Cardiorespiratory status after treatment for acute lymphoblastic leukemia. Med Pediatr. Oncol. 26, 160-165 (1996).

154. van Brussel, $M$. et al. Physical function and fitness in long-term survivors of childhood leukaemia. Pediatr. Rehabil. 9, 267-274 (2006).

155. Wallek, S. et al. Impact of the initial fitness level on the effects of a structured exercise therapy during pediatric stem cell transplantation. Pediatr. Blood Cancer https://doi.org/10.1002/pbc.26851

156. Warner, J. T., Bell, W., Webb, D. K. H. \& Gregory, J. W. Relationship between cardiopulmonary response to exercise and adiposity in survivors of childhood malignancy. Arch. Dis. Child. 76, 298-303 (1997).

157. Wiernikowski, J. T. et al. Alendronate for steroid-induced osteopenia in children with acute lymphoblastic leukaemia or non-Hodgkin's lymphoma: results of a pilot study. J. Oncol. Pharm. Pract. 11, 51-56 (2005).

158. Wright, M. J., Hanna, S. E., Halton, J. M. \& Barr, R. D. Maintenance of ankle range of motion in children treated for acute lymphoblastic leukemia. Pediatr. Phys. Ther. 15, 146-152 (2003).

159. Wright, M. J., Twose, D. M. \& Gorter, J. W. Gait characteristics of children and youth with chemotherapy induced peripheral neuropathy following treatment for acute lymphoblastic leukemia. Gait Posture 58, 139-145 (2017).

160. Wright, M. J. F. S. M. Adaption and psychometric properties of the gross motor function measure for children receiving treatment for acute lymphoblastic leukemia. Rehabil. Oncol. 25, 14-20 (2007).

161. Wright, M. J., Galea, V. \& Barr, R. D. Proficiency of balance in children and youth who have had acute lymphoblastic leukemia. Phys. Ther. 85, 782-790 (2005).
162. Wright, M. J., Halton, J. M. \& Barr, R. D. Limitation of ankle range of motion in survivors of acute lymphoblastic leukemia: a cross-sectional study. Med. Pediatr. Oncol. 32, 279-82 (1999).

163. Wright, M. J., Halton, J. M., Martin, R. F. \& Barr, R. D. Long-term gross motor performance following treatment for acute lymphoblastic leukemia. Med. Pediatr. Oncol. 31, 86-90 (1998).

164. Zaccara, A. et al. Gait analysis in patients operated on for sacrococcygeal teratoma. J. Pediatr. Surg. 39, 947-952 (2004). Discussion 947-52.

165. Wurz, A., Chamorro-Vina, C., Guilcher, G. M. T., Schulte, F. \& Culos-Reed, S. N. The feasibility and benefits of a 12-week yoga intervention for pediatric cancer outpatients. Pediatr. Blood Cancer 61, 1828-1834 (2014).

166. Kaatsch, P., Grabow, D. \& Spix, C. (Eds.). German Childhood Cancer RegistryAnnual Report 2017 (1980-2016) (Institute of Medical Biostatistics, Epidemiology and Informatics (IMBEI) at the University Medical Center of the Johannes Gutenberg University Mainz, 2018).

167. Smith, J. J. et al. The health benefits of muscular fitness for children and adolescents: a systematic review and meta-analysis. Sports Med. 44, 1209-1223 (2014).

168. Stone, D. S., Ganz, P. A., Pavlish, C. \& Robbins, W. A. Young adult cancer survivors and work: a systematic review. J. Cancer Surviv. 11, 765-781 (2017).

169. Solway, S., Brooks, D., Lacasse, Y. \& Thomas, S. A qualitative systematic overview of the measurement properties of functional walk tests used in the cardiorespiratory domain. Chest 119, 256-270 (2001).

170. Wurz, A. \& Brunet, J. The effects of physical activity on health and quality of life in adolescent cancer survivors: a systematic review. JMIR Cancer 2, e6 (2016).

171. Vuotto, S. C. et al. Impact of chronic disease on emotional distress in adult survivors of childhood cancer: a report from the Childhood Cancer Survivor Study. Cancer 123, 521-528 (2017).

172. Coombs, A., Schilperoort, H. \& Sargent, B. The effect of exercise and motor interventions on physical activity and motor outcomes during and after medical intervention for children and adolescents with acute lymphoblastic leukemia: a systematic review. Crit. Rev. Oncol. Hematol. 152, 103004 (2020).

(i)

Open Access This article is licensed under a Creative Commons Attribution 4.0 International License, which permits use, sharing, adaptation, distribution and reproduction in any medium or format, as long as you give appropriate credit to the original author(s) and the source, provide a link to the Creative Commons license, and indicate if changes were made. The images or other third party material in this article are included in the article's Creative Commons license, unless indicated otherwise in a credit line to the material. If material is not included in the article's Creative Commons license and your intended use is not permitted by statutory regulation or exceeds the permitted use, you will need to obtain permission directly from the copyright holder. To view a copy of this license, visit http://creativecommons. org/licenses/by/4.0/.

(c) The Author(s) 2021 